\title{
Design and Implementation of a Wired Intercommunication Prototype for Hospital Care
}

\section{Diseño e Implementación de un Prototipo de Inter- comunicación por Cable para el Cuidado en Hospitales}

http://dx.doi.org/10.17981/ingecuc.14.1.2018.9

Research article. Submission date: 03/12/2017. Acceptance date: 02/03/2018.

\author{
Víctor Eduardo Vélez Vargas \\ Universidad Tecnológica de Pereira. Pereira (Colombia). \\ vicedveva@utp.edu.co \\ Carlos Alberto Henao Baena \\ Centro de Atención Sector Agropecuario, SENA - Tecnoparque- Nodo Pereira, \\ Línea de Electrónica y Telecomunicaciones. Pereira (Colombia). \\ c_henao_86@hotmail.com \\ Andrés Felipe Calvo Salcedo \\ Universidad Tecnológica de Pereira. Pereira (Colombia). \\ afcalvo@utp.edu.co
}

To cite this article:

V. E. Vélez Vargas, C. A. Henao Baena \& A. F. Calvo Salcedo, "Design and Implementation of a Wired Intercommunication Prototype for Hospital Care", INGE CUC, vol. 14, no. 1, pp. xx-xx, 2018. DOI: http://doi.org/10.17981/ingecuc.14.1.2018.9

\begin{abstract}
Introduction- In health centers, communication between the medical staff and the patient is generally performed by an intercom. Some of these devices have evolved in order to simplify the duty of medical staff by introducing indicator systems that allow to report which rooms demand medical service. However, they present technical weaknesses, for example, high energy consumption or high loss of information packets.
\end{abstract}

Objective- Design and build an instrumentation and a measurement prototype for hospital care that demands less energy consumption and gives a wide range of data transmission when compared to the works proposed in the literature.

Methodology- In synthesis, the prototype uses a network of switches for emergency call generation. These are sent to an intercom which enables a channel. Then, the information is processed and transmitted to every visualization module through a microcontroller and an RS-485 serial communication bus. Finally, this information is decoded and displayed in a light indicator.

Results- The testing protocol evaluates and compares the operation, performance and reliability of the equipment to that similar equipment in the same time window. A reading of energy consumption and loss of data packets was performed. In addition, a random experiment was carried out and the results were modeled from a Poisson stochastic process. The results showed a decrease of power consumption in a stable regime of $91 \%$ in comparison to the results mentioned in the literature. On the other hand, the equipment presented an information loss rate under $4 \%$ of average.

Conclusions-The design process included a hardware and software strategy which allowed to reduce the energy consumption of the display module in a steady state and increased the equipment's reliability. Furthermore, the equipment is technically efficient, scalable and maintenance friendly.

Keywords- Intercom, hospital care, Poisson Stochastic Process Microcontroller, Display, Turn-O-Matic.

\section{Resumen}

Introducción- En centros de salud la comunicación entre el personal médico y los pacientes en general se lleva a cabo por medio del intercomunicador. Algunos de estos dispositivos han evolucionado simplificando los trabajos del personal asistente del hospital, introduciendo sistemas indicadores que permiten informar la habitación que demanda servicio médico al público, sin embargo, presentan debilidades técnicas como el alto consumo energético y la pérdida significativa de paquetes de información.

Objetivo-Diseñar y construir un prototipo de instrumentación y medida para el cuidado en hospitales, que demande un gasto energético menor, y un mayor alcance en la transmisión de datos que los propuestos en la literatura.

Metodología- En síntesis, el prototipo utiliza una red de interruptores para la generación de las llamadas de emergencia, estas son enviadas a un intercomunicador el cual habilita un canal; luego la información es procesada y transmitida a los módulos de visualización por medio de un microcontrolador y un bus comunicación serial RS-485, finalmente esta información es decodificada y visualizada en un indicador luminoso.

Resultados- El protocolo de prueba consistió en evaluar y comparar el funcionamiento, el rendimiento y la confiabilidad del mismo con un equipo similar en la misma ventana de tiempo. Se realizaron lecturas de consumo energético, pérdida de paquetes de datos y se implementó un experimento aleatorio cuyos resultados fueron modelados a partir de un proceso estocástico de Poisson. Los resultados arrojaron una disminución del consumo energético en régimen estable de $91 \%$ en comparación a lo expuesto en la literatura. Por otro lado, el equipo presenta una tasa de perdida de paquetes de información menor al $4 \%$ en promedio.

Conclusiones- El procedimiento de diseño contempla una estrategia por hardware y software que permite disminuir el consumo energético de módulo de visualización en estado estable y aumentar la confiabilidad del equipo. Además de ser eficiente, el equipo es escalable y de fácil mantenimiento.

Palabras clave- Intercomunicación Atención Hospitalaria, Proceso Estocástico Poisson, Microcontrolador, Visualizador, contador. 


\section{INTRODUCTION}

Modern electronics has allowed the development of customizable applications for user's desires. These applications provide solutions to different known requirements at a relatively low investment cost. Smart systems have been widely used in different sectors like agriculture, medicine, mining and others areas [1]. For specific applications directed to public and customer attention, it's common to find Turn-O-Matic systems (also known as Take-a-number or Digital Turn system) that help to release the bottleneck caused by delays and big service demand [2]. The Turn-O-Matic systems with seven segment displays has been an alternative for these problems.

Generally, in health institutions, the Turn-O-Matic systems have been adapted for different scenarios where the service quality is fundamental. Usually, hospital and health centers have communication equipment (intercom) between rooms and medical staff. This device attempts to a quick patient attention; however, this solution has visualization issues that generate an inadequate alert for the medical staff. In addition, the nursing care request models between the patient and the assistance personnel do not involve the general public (family members, friends, among others) [5]. There are some cases that use cloud technology to generate reports and turn changing, but this solution brings new issues such as channels limitation and high costs, among other things [6]-[8].

The technology designed for these systems is varied, although it can be classified depending on the environment of information transfer. For example, in [23] the authors proposed a wireless system for nursing calling in health centers, the equipment is designed for large health centers. The system uses a sturdy communication protocol where alarms can be installed and also uses communication by sound. Similarly, the authors from [24] designed and implemented a wireless system for customer service, which has extra functions from [23]. For instance, the service attention command is sent in redundant mode to the nursing station and the mobile phone of the duty officer is sent by a text message. These approaches are also represented in [26]-[27].

On the other hand, [25]-[28] reported nurse calling under a different model that assigns the medical staff depending on the profile of the patient. It uses sensors and other devices for user monitoring and gives an automatic attention order. One feature of the mentioned works is that they operate under a custom service paradigm, which denies the general public from the model and it does not keep the equipment's technical validation. In other words, energy demand, reliability, channels' number, and other features of the system are not clear.

In [5], [9] the authors introduced a variant that shows an alternative model for hospital care commu- nication which includes other actors related to the patients (family and friends). Although they proved a prototype's technical validation, it has bounds, for example, high energy consumption and significant loss of data packets, which affect the equipment's functionality. This paper shows an instrumentation and wired measurement system directed to improve some of the weaknesses before described while keeping the same application approach for wired hospital care. This approach used the advantage of the communication protocol RS-485 for data transmission and reception. The approach retains the simplicity and some elements of the methodologies presented in [5], [9], [23], [24]. However, this approach highlights the flexibility, scalability and reliability of the equipment from a software and hardware strategy. Additionally, a software procedure that allows to optimize the energy consumption in a stable regime of the display module improving the work reported in [9] is proposed in this paper.

This article is organized as follows: Section II shows the state of the art; section III presents the methodology and the detailed design of each methodology stage, starting with the intercom and ending with the visualization module; section IV presents the test protocol and documents of the performed experiment as well as the corresponding results; finally, section $\mathrm{V}$ presents the conclusions of the experience.

\section{State OF ART}

For the last decades, different Turn-O-Matic systems that use modern visual technology have been developed [2]-[3]. In 2008, [2] describes the design for a Turn-O-Matic system with display and advertising features. Similarly, in [3], a Turn-O-Matic system which uses dual segment display controlled by a TCI/IP server that generates statistical reports is proposed. Even though these applications show high performance and they also have additional services for complex tasks, their installation would demand the hospital to make a total renewal of its infrastructure, hence, making this process costly and hard to implement. In addition, their designs would require a displayer for information points. In [4], the design of three-display Turn-O-Matic system for the management of one hundred orders is proposed. Although, this is a reliable and low-cost design, the application has the limitation of not being portable and it also has scalable development problems. In the field of hospital care, there are companies that give solutions to this type of requirements because they design systems that are connected to the cloud, which has the possibility to generate reports, turn changing, among other benefits [6]-[8]. However, these solutions are expensive, limited in channels and require software for their operations, therefore, they are costly and non-adaptable. Also, they are limited in multiple information points. 


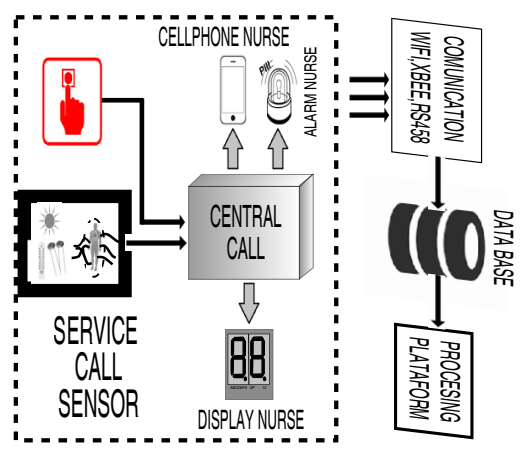

Fig. 1. General methodological diagram. Source: Authors.

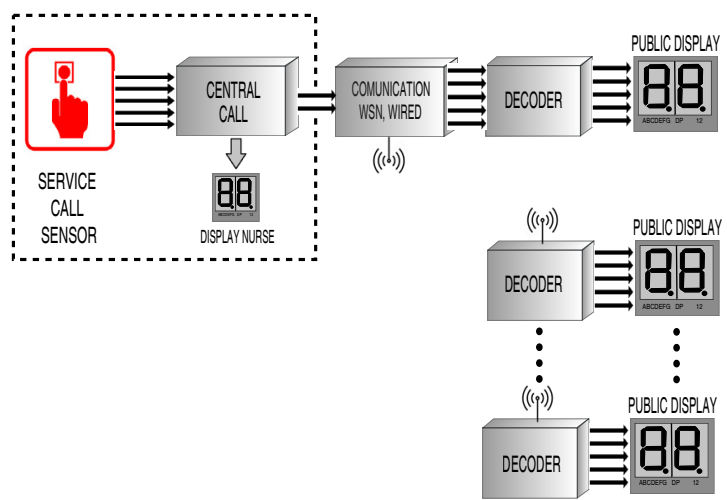

Fig. 2. Optional methodological diagram. Source: Authors.

The traditional designs of communication protocol for hospital care are summarized in the diagram of Fig. 1. It is important to highlight that the communication is only between the medical staff and the patient through different devices (LCD, display, cellphone, among others) [23]-[28].

On the other hand, the work scheme from [5], [9] is showed in Fig. 2. The main difference between these works is associated to the use of cables for data transmission. The implemented scheme in [9] uses WSN which brings big benefits for installation, scalability, adaptability and modularity of the system. However, it has technical issues associated to the electrical demand and the loss of data packets related to the range and consumption of the antenna. The work from [5] is simple and cheap, however, it does not have scalability as they did not define a communication protocol for data management. Therefore, it is unlikely the system can develop over time.

Notice the block diagrams from Fig. 1 and 2. They have some similarities in many stages as well as in technical features and functions. Nevertheless, they differ in the functional model from intercoms in a hospital environment because one of them articulates other people (public) while doing the service request process for the patient who recovers. Therefore, the technical problems must be fixed to secure a high system performance.

\section{Methodology}

This section describes the creation of the prototype. There is an emphasis in the design of each stage, both in the hardware and software level. In addition, the electronic components are specified and the strategy to evaluate the prototype performance is also presented.

\section{A. Building the Wired Measurement System}

Fig. 3 shows a block diagram with the proposed prototype structure, where $M(t)$ is the input signal of the system and $y(t)$ is the corresponding response (message showed on the display module) that is equivalent to $M(t)$. It is important to clarify that serial communication is associated to the communication protocol and the hardware component which operates the data flow of the system, i.e. this section controls the information traffic between the controller and decoder through the terminals $\mathrm{Tx}$ and $\mathrm{Rx}$ that are preserved in all data bus. The main difference with the diagram from Fig. 2 should be noticed. It is related to how the serial communication module is used since this work adopted a wireless rule which is managed by a software strategy to improve the equipment's performance when the information flow does not occur.

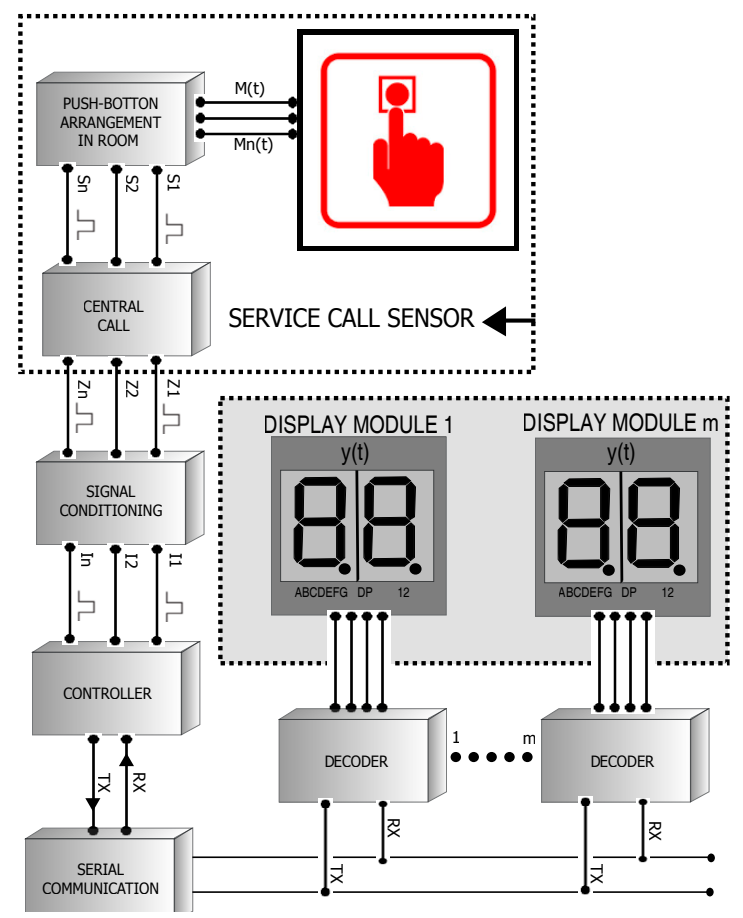

Fig. 3. Proposed methodological diagram. Source: Authors. 
The system aims to send the data towards the display module with light indicator by using an asynchronous serial communication protocol. It should be noted that this approach combines elements presented in [5], [9]. First, the modularity, because the design considers several elements by hardware that are coupled by means of a communication protocol. Note that the system portability and installation process in a real scenario is impaired due to connections from the serial communication stage to the place where we want to install the new display module.

On the other hand, it should also be noted that the methodology involves the linking of a new display module to the system from the coupling of the latter to the communication network where the prototype operates, thus, allowing the addition of indicators according to the need. This is an important feature that must be guaranteed in the design as it is desirable that the system can be scaled to small and large health centers and also that it can grow over time without altering the methodological design of the equipment. The procedure uses the push-button and intercom network structure because they are traditional resources available in almost every health centers. From a technical point of view, the system is coupled into the technological infrastructure of the health center [5].

The following procedure is the design of each stage shown in the diagram of Fig. 3. Moreover, the description of the software and hardware strategy implemented with the purpose of reducing the energy consumption of the visualization modules are also presented.

\section{B. Design}

The following design preserves several elements reported in [5], [9], therefore, in this paper only a short description of it is done. The design process begins by defining the stage that captures the service request and ends by indicating the information to the general public.

Service Call Sensor: Previous works report the use of switches (in Pull-Up mode) as actuators that allow generating attention orders from the waiting room to the intercom. Once the switches are activated, the respective voltage signal is transmitted $\{\mathrm{S} 1, \mathrm{~S} 2, \ldots, \mathrm{Sn}\}$ and they active the intercom outputs $\{$ Input $1, \ldots$. Input $\mathrm{n}$ \}. The intercom can be defined as a scaled telephone central. The moment the intercom gets the voltage signal $\{\mathrm{S} 1, \mathrm{~S} 2, \ldots, \mathrm{SN}\}$ from the recovery room, it activates a respective output channel $\left\{Z_{1}, Z_{2}, \ldots, Z_{n}\right\}$. The time the channel is still activated depends on the manual deactivation performed by the nurse in charge of the intercom operation. A circuit model that summarizes the above process is shown in Fig. 4, and it is important to clarify that intercoms have others features which are not presented in this work, however, readers can refer to [12], [13] for more detail.

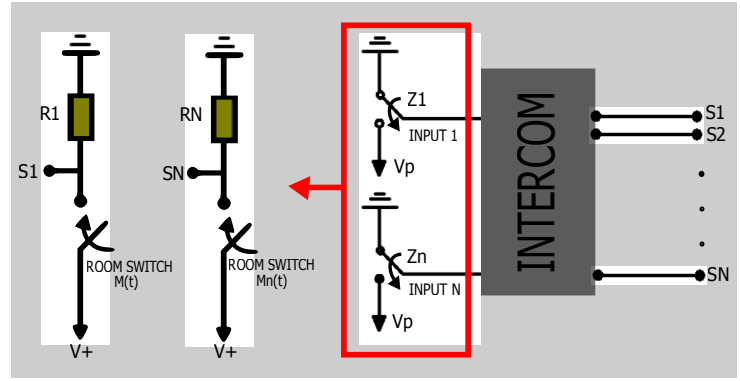

Fig. 4. Service call sensor. Source: [5], [9].

Signal Conditioning: The signal conditioning stage has a main purpose in this application which is to erase the magnetic compatibility problems between the intercom and the other elements of the interconnection system. This basically consists of operational amplifiers in follower voltage mode and optocouplers as the ohmic isolation stage between the modules to be articulated. The circuit's diagram is shown in Fig. 5. Note that $R_{p}$ resistor operates in pull-down mode. This configuration avoids the saturation phenomenon in the operational amplifier when the non-inverting door does not have electrical connection to the intercom (reserve input $Z_{n}$ free), therefore, it is suggested that its value will be equal to kilo-ohms.

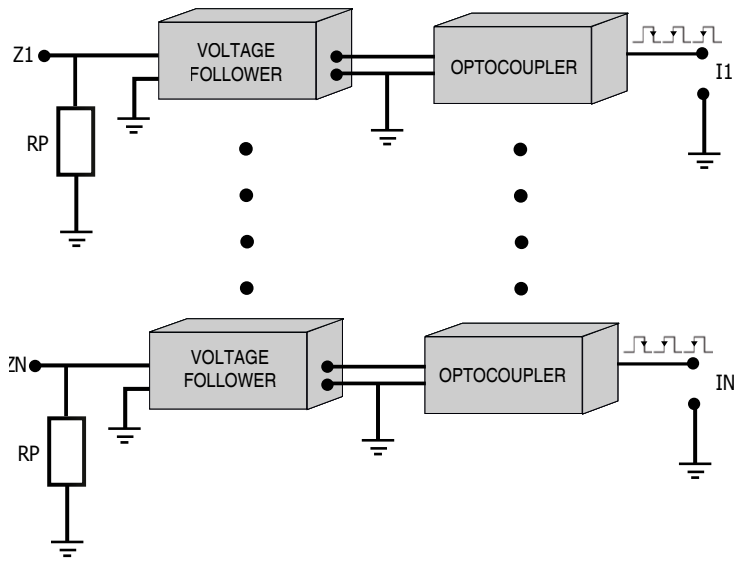

Fig. 5. Signal conditioning stage. Source: [5].

Controller: This module is responsible for taking attention orders (preconditioned) supplied by the Service Call Sensor, and then, encrypting and transmitting this information through a serial protocol communication to all the display modules. Note that in this case, through the same intercom, several display modules can converge. Nonetheless, these modules cannot share the information between them and this is only possible with the system intercom given by the Service Call Sensor module. 
This shows a characteristic of networks in pointto-multipoint topology. The circuit's diagram of the Controller stage is shown in Fig. 6.

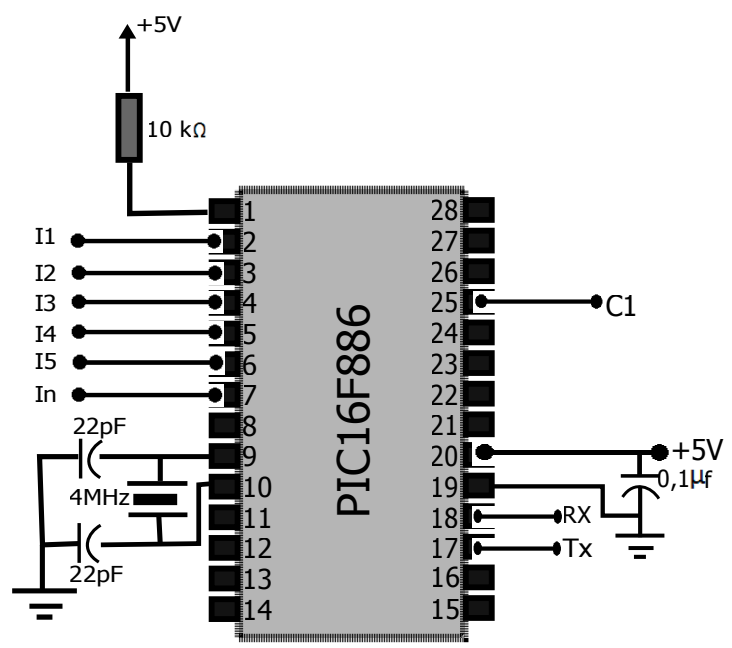

Fig. 6. Controller stage. Source: Authors.

The terminals [I1 ...In] correspond to the outputs supplied by the circuit in Fig. 5. On the other hand, the $\mathrm{Rx}$ and $\mathrm{Tx}$ terminals are used by default for the serial communication implementation. The selected processing device consists of a microcontroller PIC16F882, which is an easily accessible and universal device, and has the resources for the implementation of the application. Although, it was decided to use other control element, it is recommended to use the following hardware level resources:

- An EUSART Asynchronous Transmitter-Receiver module.

- Multiple digital inputs.

When comparing the number of inputs that can be supported, the proposal establishes other alternatives than those reported in [5], [9] by considering a Pic microcontroller of the family $16 f 88 x$. Table 1 sets forth the information regarding the available terminals.

Table 1 Proposed available terminals.

\begin{tabular}{|c|c|}
\hline Alternative & Number of available terminals \\
\hline Presented in [5] & $n-17$ \\
\hline Presented in [9] & $n-9$ \\
\hline Presented in this paper & $n-10$ \\
\hline
\end{tabular}

Source: Authors.

As seen, $n$ parameter refers to the number of microcontroller terminals to be used. In others words, for 40 microcontroller terminals, the proposal presented in [5] would have 23 inputs. This paper suggests 31 inputs due to the fact that the system preserves the modularity concept in [9], where the authors articulate the data acquisition process with the display module through a communication protocol. The terminal function [12] from Fig. 6 defines the next section.

Serial Communications: The prototype reported in [5] has a data line per channel, i.e. for each visualization module it is necessary to take the channels [I1, ..., In]. Therefore, the more the inputs, the greater the volume of terminals to be interconnected. This amount can be reduced by implementing a communication protocol that allows to transport the data in a wire to each visualization module of the system. This process can be achieved by using a serial communication protocol. In the literature, there are synchronous and asynchronous serial protocols. The first one needs a clock reference signal that is in charge of synchronizing the communication between the elements that conform the network. This protocol has interesting advantages such as a fast and robust performance against attacks and low energy consumption, however, it is limited in distance (30 $\mathrm{cm}$ as maximum). Some synchronous serial communication protocols examples frequently used in practice are the SPI and I2C standards [15]. On the other hand, the asynchronous serial protocols do not need a clock signal to synchronize the communication process, i.e. there is no relationship in time between the sending device and the receiving device. Although this protocol has low performance in data transmission, it has advantages that are attractive in application with considerable distances as some standards support approximately up to $1.2 \mathrm{~km}$ in data transmission [10].

The RS-232 standard is one of the most representative examples of the asynchronous serial protocol, which was introduced in the 60's, because it establishes a communication at relatively low speed. However, it has two limitations: the first one is conformed of a master and a slave device, i.e. only two devices participate in the communication process. The second one is a limited range of approximately 15 $\mathrm{m}$ [16]. However, there is an option for this standard that allows to overcome the mentioned limitation: linking and articulating a hardware stage in the communication process, known as RS-485 standard. The standard achieves a maximum distance that can exceed thousands of meters and allowing serial communication with multiple slave devices connected to their respective data bus. Additionally, it has other advantages such as higher speed in information transfer than the RS-232 standard and robustness to electromagnetic interference, which is important for applications with contaminated industrial environments [11]. This paper uses an asynchronous serial communication protocol, more precisely, the RS-485 standard in order to build a point-to-multipoint network that allows to transmit information to each visualization module of the system. The circuit diagram is shown in Fig. 7. 


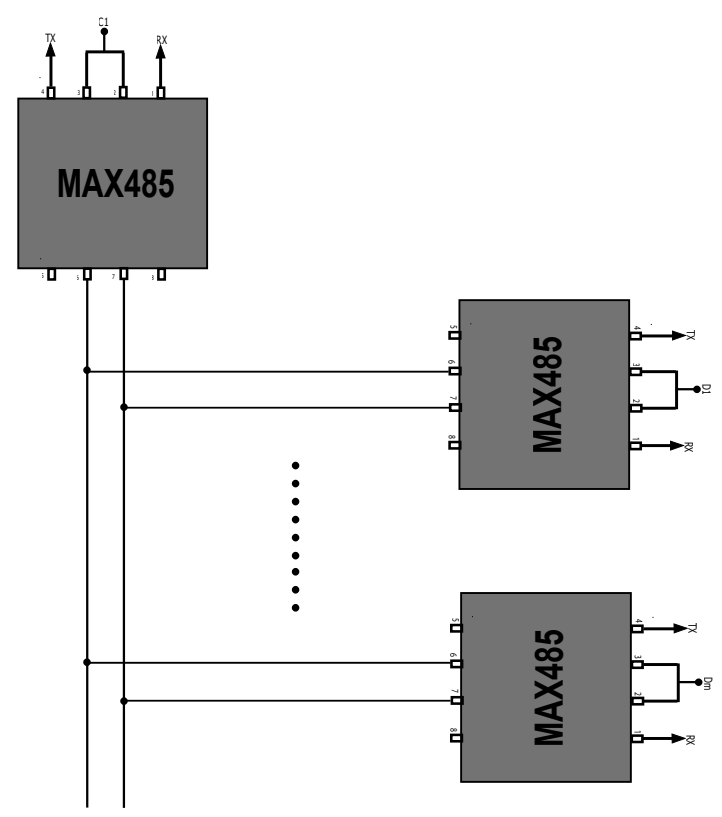

Fig. 7. Serial communications diagram. Source: Authors.

As shown, vector [Tx $\mathrm{Rx}$ ] corresponds to the terminals used by the master and slave microcontrollers to transfer and receive information in the network. It is important to clarify that the MAX485 integrated function converts the voltage levels delivered by the microcontroller in voltage levels that are in the RS-485 standard and vice versa. Thus, terminals [Tx Rx] are conserved in the communication process. Picking the MAX485 was essential because it is accessible, robust and easy to implement. Finally, terminals [C1, D1, DM] must be handled with care because they control the function of each module (data transmission and reception) [14].

Decoder: The decoding stage receives, extracts and processes the data delivered by the serial communication channel to finally send the visualization element to the room that requests medical service. The proposed circuit to this purpose is shown in Fig. 8, in which the terminals [Rx Tx Dm] are represented in Fig. 7. On the other hand, the terminals [Mux1 Mux2] correspond to the control terminals of the visualization element. And finally, the outputs [OUT1, OUT2, ..., OUT8] correspond to the data lines where the information is transmitted to the display module. It is noteworthy that the control element corresponds to a PIC16F886 microcontroller, though another machine can be used. However, it is recommended to have the following minimum features at a hardware level.

- EUSART Asynchronous Transmitter - Receiver Module.

- Interruptions due to overflow of timer

- Input and output terminals for coupling with the visualization element.

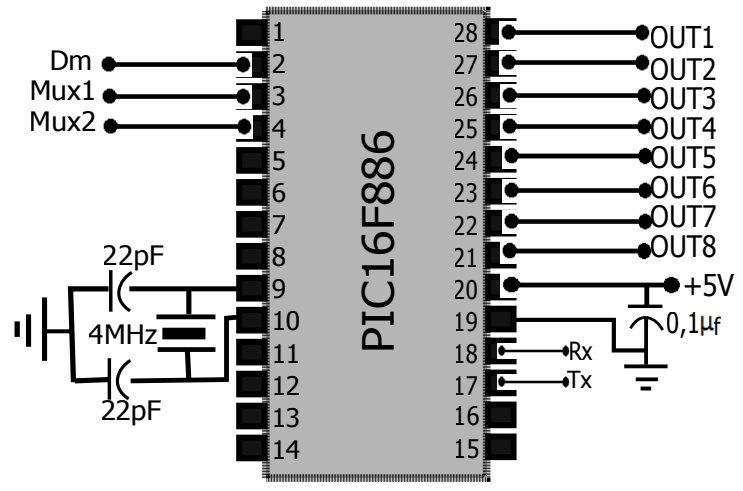

Fig. 8. Decoder stage. Source: Authors.

Display Module: It is used to inform the room that requests medical service. This consists of a dual segment cathode display, a microcontroller and a power stage made up transistor in a BJT logic inverted configuration. Note that in this case, the terminals [OUT1 ... OUT8] correspond to the circuit outputs from Fig. 8, while the transistor's ON and OFF control commands are archived by the terminals [Mux1, Mux2]. For more details on the operating system from Fig. 9, turn to [15].

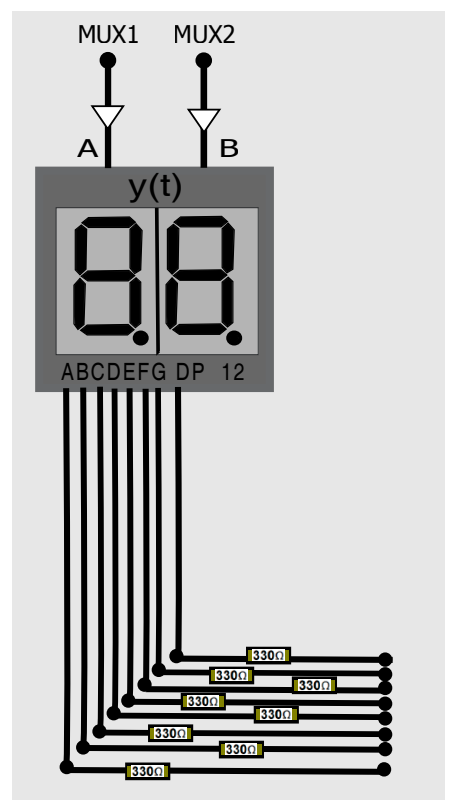

Fig. 9. Display module stage. Source: [9].

Software: The system must operate under the supervision of an algorithm, which must have the capacity to capture, encode, transmit, receive, decode and inform the room reported by the system's microcontroller. Therefore, the software must be implemented into the master microcontroller (Controller) of the system and each slave microcontroller (Decoder) 
that conform the point-to-multipoint network. This one is in charge of capturing, encoding and sending the information channeled by the intercom. The second algorithm is in charge of receiving, decoding and reporting the room that request a medical service. The elaboration is implemented in a PIC $\mathrm{C}$ environment, a $\mathrm{C}$ language adaptation for $\mathrm{PIC}$ microcontrollers [15].

Fig. 10 shows the algorithm associated to the controller stage. Note how the master sends three data when the attention order is generated. This is necessary to implement a strategy that allows to reduce the energy consumption of each visualization module.

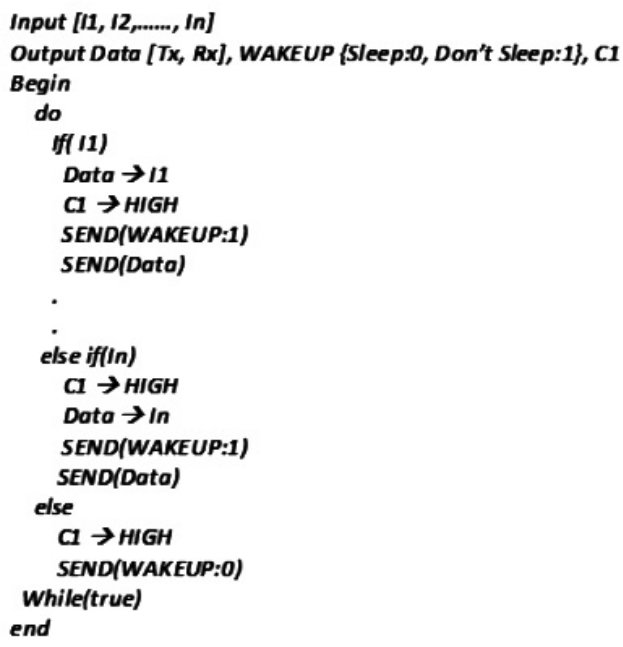

Fig. 10. Master algorithm of the system. Source: Authors.

The algorithm associated to the decoder stage is shown in Fig. 11. In this case, the concept of interruptions is used, where the first one corresponds to the interruption by data reception in the microcontroller's EUSART [15], allowing to disable the low energy consumption mode of the decoder when receiving the signal WAKE UP [17]. When the microcontroller stops the hibernation mode, it takes the information to be decoded. Then the information is sent to the light indicator of the respective visualization module. Finally, once the command has been answered, the controller sends to each slave the command to turn the indicators and enters again in low power consumption mode as the strategy that decreases the energy consumption of the visualization system when it does not exist attention commands by the user is specified. All this is possible when EUSART is into the visualization element. To end, the interruption by the TMR0's overflow controls the $\mathrm{ON}$ and $\mathrm{OFF}$ of the indicator with the purpose of eliminating the blinking.

This strategy does not consider a simultaneous attention of the commands channeled by the intercom, although this can be modified according to the requirements established at the time by the respective client which will impart the characteristics of the system. Clearly, this implies adjustments in the operating algorithms of the system. However, the methodology works without alterations. Lastly, the system is scalable as the RS485 standard adapts several visualization modules to the same master, which in turn can take the information to different places of the health center.

Emulo Intercom: To complete the plan, it is necessary to define the element that enables the communication between the medical staff and the respective client (intercom). The function introduced in Fig. 4 can be emulated by a digital circuit based on a microcontroller. This is shown in Fig. 12. In this way, when one of the signals from figure 1 is activated [S1, S2, ..., SN], they are immediately captured by the input terminals of the microcontroller. Then, depending on the captured signal, the respective output $[\mathrm{Z1}, \ldots, \mathrm{Zn}]$ is triggered. The selection of the PIC16F886 microcontroller from Fig. 12 is arbitrary as the process can be performed by almost any general-purpose microcontroller.

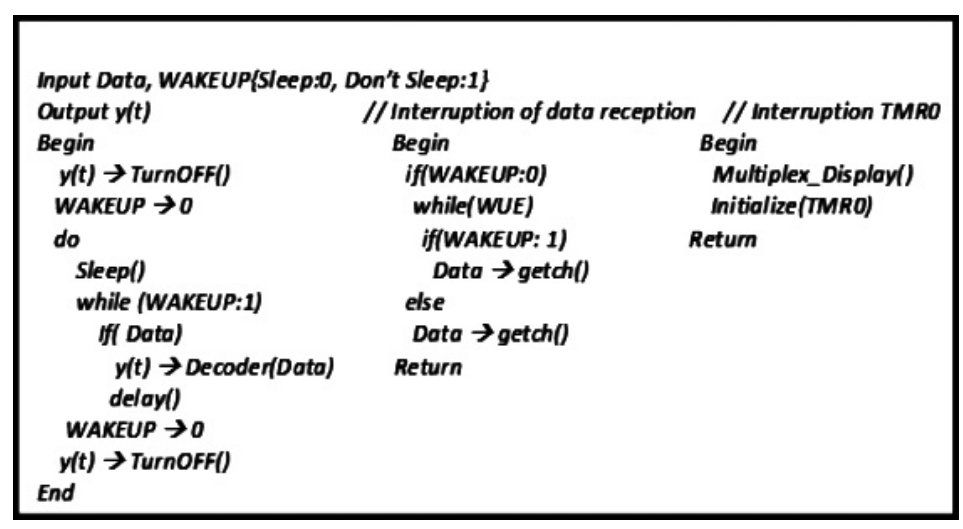

Fig. 11. Algorithm of the decoder element of the system. Source: Authors. 


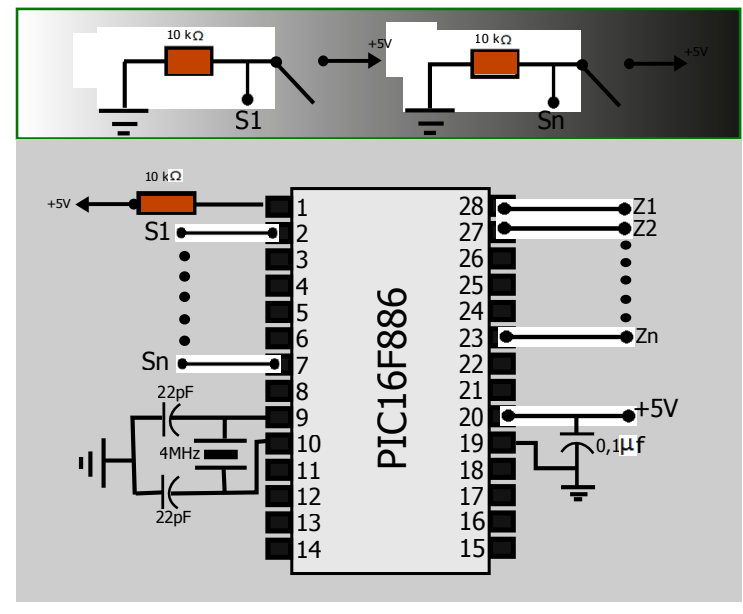

Fig. 12. Emulator intercom. Source: [9].

Validation Process: This section describes the structured processing to validate the performance of the suggested design. Experiments are performed to quantify energy consumption, loss rate of data package and prototype reliability.

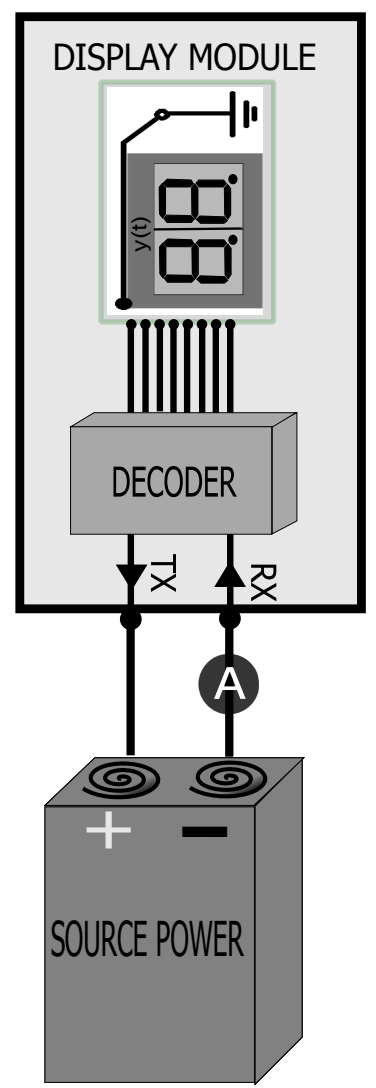

Fig. 13. Power consumption measurement circuit of the visualization module. Source: [9].
The energy consumption measured corresponds to the quantity of consumed electrical energy for the display module, decoder and the serial communication's hardware stages. Other elements are ignored because they must be in latent mode during functioning, therefore, their consumption is assumed to be uniform. Thus, measurements were taken during the excitation operating state (Wake up) and the in-steady state (Sleep). The circuit measurement basically conditions an ammeter (A) in line to the power source and the module, as shown in Fig. 13. On the other hand, the distance variation effect was considered; therefore, different tests were performed by changing the communication channel length. The experiment was repeated 10 times (40 readings) to assess the repeatability of the measurements.

To quantify the information transfer performance, a random experiment on data packets loss, transmitting commands between the Controller (network coordinator) and the Decoder modules (Slaves Network) is carried out [20]. This test seeks to evaluate the sturdiness of the serial communication stage for different ranges and decide on how safe the implemented protocol is.

For system reliability calculation, a random experiment was carried out. First, attention requests for different instances of time were generated $\left[M(t), \ldots M_{n}(t)\right]$. Then the number of occasions when the equipment failed was counted (refers the number of times when it was not possible to show in some display modules the message sent by the controller). The objective of this test was to evaluate the main function of the equipment and determine the probability of failure as a function of time. The above is very important because the reliability must be evaluated without restricting the issue which causes damage.

Now, a failure of functionality is considered when the order $\mathrm{Mn}(\mathrm{t})$ does not produce the corresponding output $\mathrm{yn}(\mathrm{t})$, which can occur due to many factors, therefore the event $[\mathrm{Mn}(\mathrm{t})$ and $\mathrm{n}(\mathrm{t})]$ it is independent of the event $[\mathrm{Mm}(\mathrm{t}) \mathrm{Ym}(\mathrm{t})]$ because it is not of interest in this work to determine the origin of the error.. Therefore, the probability that the equipment does not work can be molded by a Poisson random process, which is shown in (1) [21]-[22].

$$
P(X=k)=\frac{(t)^{k} e^{-\lambda t}}{k !}
$$

Where, $X$ is the random variable, $t$ corresponds to the time the process lasts and $\lambda$ is the parameter which quantifies the failure rate. Given the above, $t>$ o $y \lambda \geq 0$. Then, with the amount of failures occurred while the last experiment operated, the value of $\lambda$ can be tuned with the maximum likelihood estimator (2) [19]-[22].

$$
\lambda=\frac{\sum_{i}^{j} k_{i}}{p t}
$$


$k_{i}$ corresponds to the failure detected in the instant $t_{i}$ and $p$ is the total number of equipment (Number of identical prototypes that are being tested for functionality) which is being evaluated. The mean value and theoretical variance that are above the random variable $X$ are given by the first and second statistical moment of the Poisson stochastic process, this is $\mu=\lambda t$ and $\sigma^{2}=\lambda t$. Then, the process is completely described while calculating the reliability from [9].

The described experiments will be performed simultaneously with the equipment showed in [9]. Unfortunately, the proposal presented in [5] is ignored because is not scalable, i.e. this work does not have a protocol that allows to interconnect more than one display module. Hence, the results cannot be compared. A similar situation associated to the model is presented in [23]-[28].

\section{RESUltS}

In order to evaluate the equipment's performance in real conditions, it was sought to emulate the hospital environmental conditions. This type of environment has corridors, walls, electrical network, electronic systems and signal with electromagnetic noise, e.g. WI-FI. For this reason, the test is carried out at the headquarter building of the Universidad Tecnológica de Pereira because this building meets those characteristics. Then, two Display Modules were installed using the proposed design. In addition, a 4 -input signal system was built $\left[M(t), M_{1}(t)\right.$, $\left.M_{2}(t), M_{3}(t)\right]$ to verify the equipment's performance. The circuits that made everything possible are shown in Fig. 14.

In Fig. 14, A is the card that contains the controller, signal conditioning and serial communications stages; $\mathrm{B}$ is the $[\mathrm{Z1}, \ldots, \mathrm{Zn}]$ signal; $\mathrm{C}$ is the signal conditioning stage; $\mathrm{D}$ is the controller stage; $\mathrm{E}$ is the serial communications protocol; and $\mathrm{F}$ is the decoder and display module card. According to Table 2, it can be established that the energy consumption is independent of the distance between the transmission

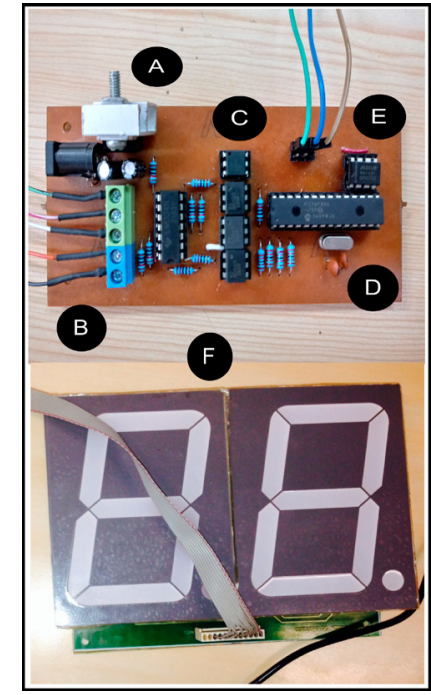

Fig. 14. Circuit implementation of the proposed design Source: Authors.

and reception equipment. Also, it can be observed a low energy consumption of the different modules in their operation state and stable mode. During the development of this experiment hot spots or system restarts were not reported since, due to the equipment's low energy consumption, the system can operate for long periods of time. Making a comparison with the methodology proposed in [9], there was a decrease of $51 \mathrm{~mA}$, that is equivalent to a $79 \%$, in operation mode. For the stable mode, a decrease of $41 \mathrm{~mA}$ was observed, which is equivalent to a $91 \%$. These results allow to validate the strategy taught in Fig 10 and 11. Note that the difference in energy consumption between prototypes is mainly due to the fact that the system antennas proposed in [9] must always be latent because the medical service orders correspond to a random event. Standard deviation was not reported because a variation on the electric current readings was not observed. Table 3 shows the average packets that arrive at the receiver modules for different distances.

TAble 2. Outcome Results vs Energy consumption of the Visualization module.

\begin{tabular}{|c|c|c|c|c|c|}
\hline \multirow{2}{*}{ Experiment } & \multicolumn{2}{|c|}{$\begin{array}{c}\text { Current } \\
\text { methodology }\end{array}$} & \multicolumn{2}{c|}{$\begin{array}{c}\text { Methodology } \\
\text { proposed in [9] }\end{array}$} \\
\cline { 2 - 6 } & \multicolumn{2}{|c|}{ Consumption } & \multicolumn{2}{c|}{ Consumption } \\
\hline $\mathrm{N}^{\circ}$ & $\begin{array}{c}\text { Distance } \\
{[\mathrm{m}]}\end{array}$ & $\begin{array}{c}\text { Operation } \\
(\mathrm{mA})\end{array}$ & $\begin{array}{c}\text { Stable } \\
(\mathrm{mA})\end{array}$ & $\begin{array}{c}\text { Operation } \\
(\mathrm{mA})\end{array}$ & $\begin{array}{c}\text { Stable } \\
(\mathrm{mA})\end{array}$ \\
\hline 1 & 10 & 14 & 4 & 64 & 47 \\
\hline 2 & 30 & 14 & 4 & 68 & 47 \\
\hline 3 & 50 & 14 & 4 & 69 & 47 \\
\hline 4 & 100 & 14 & 4 & 48 & 47 \\
\hline
\end{tabular}

Source: Authors. 
Table 3. Results of the PaCket Quantity Received as a FunCtion of the Distance.

\begin{tabular}{|c|c|c|}
\hline Distance & $\begin{array}{c}\text { Current } \\
\text { methodology }\end{array}$ & $\begin{array}{c}\text { Methodology } \\
\text { proposed in [9] }\end{array}$ \\
\hline Distance [m] & $\begin{array}{c}\text { Received } \\
\text { packets (\%) }\end{array}$ & $\begin{array}{c}\text { Taken } \\
\text { packets [\%] }\end{array}$ \\
\hline 10 & $96 \pm 3.89$ & $100 \pm 0.00$ \\
\hline 30 & $96 \pm 3.89$ & $90.30 \pm 2.70$ \\
\hline 50 & $97.69 \pm 3.57$ & $5.50 \pm 0.70$ \\
\hline 100 & $99.00 \pm 0.00$ & $0 \pm 0.00$ \\
\hline
\end{tabular}

Source: Authors.

Table 4. Reliability results through the Poisson process.

\begin{tabular}{|c|c|c|c|c|}
\hline \multirow{2}{*}{$\begin{array}{c}\text { Time } \\
\text { (Month) }\end{array}$} & \multicolumn{2}{|c|}{$\begin{array}{c}\text { Current } \\
\text { methodology }\end{array}$} & \multicolumn{2}{c|}{$\begin{array}{c}\text { Methodology } \\
\text { proposed in [9] }\end{array}$} \\
\cline { 2 - 5 } & $\begin{array}{c}\text { Probability } \\
\text { of failure (\%) }\end{array}$ & $\begin{array}{c}\text { Reliability } \\
(\%)\end{array}$ & $\begin{array}{c}\text { Probability of } \\
\text { failure (\%) }\end{array}$ & $\begin{array}{c}\text { Reliability } \\
(\%)\end{array}$ \\
\hline 1 & 98.17 & 1.83 & 99.75 & 0.25 \\
\hline 2 & 99.97 & 0.03 & 100 & 0 \\
\hline
\end{tabular}

Source: Authors.

Table 5. Results of the EXPeCted values from the failures.

\begin{tabular}{|c|c|c|}
\hline $\begin{array}{c}\text { Time } \\
\text { Period } \\
\text { (Month) }\end{array}$ & $\begin{array}{c}\text { Expected value } \\
\text { of the current } \\
\text { methodology (failures) }\end{array}$ & $\begin{array}{c}\text { Expected value of } \\
\text { the proposed } \\
\text { methodology in [9] }\end{array}$ \\
\hline 1 & 4 & 6 \\
\hline 2 & 8 & 12 \\
\hline 6 & 24 & 36 \\
\hline 12 & 48 & 72 \\
\hline
\end{tabular}

Source: Authors

Table 3 shows a low packet loss, which guarantees a high performance when sending the information to each display module to be interconnected. From these results, and with a varying distance, it is evident that the loss of information is insignificant. For 100 executions of the experiment, the standard deviation in each location was decided. To evaluate the reliability, the experiment is performed in a time window of fifteen days, varying locations and distances of the system during different hours of the day. The results show that for 400 service commands set by the room pushbutton, the system only failed twice while the contrasted equipment failed three times. Thus, the equipment under assessment proves high reliability. Using equation 1 and 2 , the adopted stochastic process is described. Then, the reliability of the equipment in a bigger time window was predicted. The probability results are shown in Table 4. It is important to clarify that the failure presented does not refer to equipment issues (electrical rupture, physic damage). Instead, it refers to the incapacity to do its main function. Table 5 shows the expected values for different moments of time.

In [9] a flawed methodology is set forth as --despite being scalable-- it has a high energy cost to work properly. Furthermore, as it is shown in table 3 , the quantity of packets received over a distance of 30 meters is not even acceptable. Consequently, it can be inferred that at greater distances the scenario will be worse. Conversely, the current methodology aims to fix all those issues and consolidate itself as a scalable prototype which is also energy efficient and, most important, one that ensures the amount of lost data packets will be less than $4 \%$ (see Table 3). 
The results from table 4, show the probability failure of the contrasted equipment. These results bring about a high probability of the equipment failing in the first month. However, there is a difference which indicates the equipment from [9] might fail in its functioning. On the other hand, the results from table 5 shows that the proposed prototype has a better performance in time than its counterpart.

Comparing the results shown in Table 2 and Table 3 , it is clear that the energy needed to operate for the current methodology is much less than the needed in [9]. Furthermore, it is important to add that the tests for each methodology were applied exactly in the same environment, hence, providing greater credibility to the results obtained.

\section{Conclusion}

Based on the results, the adopted strategy for data reception combining hardware and software components led to a decrease in energy consumption of each display module and decoder stage in stable conditions. This process is independent from the electrical characteristics of different active components to be used (display, transistors, optocouples, among others).

The wired communication protocol of this work improved the system's reliability, since it increased the number of data packets received during the transmission-reception process as well as the data transmission at considerable distances. In addition, although the solution used physical drives, these are considerably smaller than those reported in [5].

The proposal allowed to add a display module through the proposed serial communication. Although, it is a wireless connection, the modularity and scalability are still conserved. These features allowed, firstly, decentralize the energy source of the decoder and display module from the rest of the equipment. The above is very important because it eliminates the need to depend on a single source of energy. And secondly, the system can develop through time, which can be really important for big health centers.

The methodology retained the simplicity and philosophy reported in [5], [9], since it keeps the infrastructure of the health center (few parts have to be changed) and the intercom can be used as a medium to extract the attention orders without making technological adjustments for equipment installation. This low-cost option is crucial when the resources are limited.

For future works, we are interested in linking a display module stage that allows not only to inform the room that requests medical service, but also, to be able to generate different types of reports related to the user, for example, (name, treating doctor, among others), as well as advertising related to the services offered by the health care provider.

\section{Funding}

This work was supported by the Universidad Tecnológica de Pereira, through the project entitled "Hospital Messenger" Start date: July, 2015. At present day, May 2018, the project is ongoing.

\section{ACKNOWLEDGMENT}

The authors wish to thank Tecnoparque Nodo Pereira and the Universidad Tecnológica de Pereira for the support received during the development of this work.

\section{REFERENCES}

[1] Md. Atikur Rahman, "A Review on Semiconductors Including Applications and Temperature Effects in Semiconductors," American Scientific Research Journal for Engineering, Technology, and Sciences (ASRJETS), vol. 7, no. 1, pp 50-70, 2014 Disponible en: http://asrjetsjournal.org/index.php/American_Scientific_Journal/article/ view/693/519

[2] R. E. González Amaya, "Sistema digital de turnos con despliegue en panel matricial de información". Tesis de Pregrado. Facultad de Ingenierías Fisicomecánicas, Universidad Industrial de Santander, Bucaramanga, Colombia, 2008.

[3] J. D. Castro, F. M. Góngora, J. A. Rengifo y D. G. Sardi, "Mejoramiento del proceso de matriculación, mediante la implementación de un sistema tecnológico y su incidencia en la atención a los estudiantes de la Facultad de Ciencias Matemáticas Físicas y Químicas". Tesis de Pregrado. Universidad Técnica de Manabí, Ecuador, 2012.

[4] W. Yanez, "Construcción de un prototipo para el control de turnos electrónico con 6 puestos diferentes de llamada y 99 turnos", Tesis Tnlgo, Escuela de formación de tecnólogos, Escuela Politécnica Nacional, Quito, Ecuador, 2012.

[5] C. A. Henao Baena, H. B. Cano Garzón, "Diseño e implementación de un sistema de instrumentación y medida para la atención hospitalaria," Revista Ingenium, vol. 8, no. 22 , pp. 45-51, 2014. https://doi.org/10.21774/ing. v8i22.464

[6] C. Lara, A. José, "Desarrollo de un sistema de generación de turnos para atención a estudiantes de la Universidad de Guayaquil, Carrera de Ingeniería en Sistemas Computacionales". Tesis para Ph. D. Facultad de Ciencias Matemáticas y Físicas, Universidad de Guayaquil, Ecuador, 2017.

[7] S. Casado y J. Pacheco, "Diseño de un sistema para la resolución del problema de programación de turnos en un aeropuerto," Estudios de Economía Aplicada, vol. 24, no. 2, pp. 763-782, 2006. Disponible en: http://www. redalyc.org/html/301/30113180019

[8] A. M. Vaquera, "Sistema de gestión de citas en entornos de tele-asistencia y tele-seguimiento," Tesis Ing., Departamento de Ingeniería Telemática, Universidad Carlos III de Madrid, Madrid, España, 2009.

[9] A. F. Calvo Salcedo, C. A. Henao Baena y P. Y. Izquierdo Betancur, "Diseño de un sistema de instrumentación medida inalámbrica para la atención hospitalaria: una alternativa," Revista GTI, vol. 15, no. 41, pp. 33-45, 2016. Disponible en: <http://revistas.uis.edu.co/index. php/revistagti/article/view/5908

[10] N. G. Forero Saboya, "Normas de Comunicación en Serie: RS-232, 422 y RS-485," Ingenio Libre, vol. 11, no. 1, pp 86-94, 2012. Disponible en: http://www.unilibre.edu. co/revistaingeniolibre/revista-11/art13.pdf 
[11] J. L. Martínez y J. Balcells, "Autómatas Programables", Marcombo, España, pp. 126-130.

[12] A. M. Rodríguez Salazar, "Sistema inalámbrico de intercomunicador y videovigilancia para los laboratorios de electrónica de la Universidad de San Buenaventura, Medellín,” Tesis Ing., Facultad de Ingenierías, Universidad San Buenaventura, Medellín, Colombia, 2014.

[13] F. E. Muñoz Muñoz, "Seguridad electrónica un aliado en los Centros de Reclusión para Menores," Tesis Lic. Facultad de Relaciones Internacionales, Estrategia y Seguridad, Universidad Militar Nueva Granada, Colombia, 2014

[14] Z. Kai y G. Li-li, "Program for serial communication between PC and single chip microprocessor based on MAX485 [J]," Information Technology, vol. 4, no. 2, p. 3, 2005. Disponible en: http://en.cnki.com.cn/Article en/CJFDTOTAL-HDZJ200504003.htm

[15] C. A. H. Baena, H. A. G. Becerra y W. A. Ureña, Libro guí para el estudio de las interrupciones, Universidad Tecnológica de Pereira, Facultad de Ciencias Básicas, 2010.

[16] J. M. Angulo, "Diseño Práctico de Aplicaciones de Microcontroladores PIC16F877," Mcgraw-Hill, vol. 2, no. 2, pp. 14-23, 2000.

[17] Z. Yan-yan y Z. Gui-xiang, "Design of power assistant control system for intelligent electrical vehicle," Journal of Shandong University of Technology, vol. 5, no. 1, p. 26, 2010. Disponible en línea: http://en.cnki.com.cn/ Article_en/CJFDTotal-SDGC201005026.htm

[18] C. J. Zapata, "Aplicaciones del proceso de poisson en confiabilidad," Scientia et Technica, vol. 3, no. 20, pp. 171-176, 2002

[19] C. M. Bishop, "Pattern Recognition and Machine Learning,” Springer, p. 737, 2009.

[20] Xu, N., Rangwala, S., Chintalapudi, K. K., Ganesan, D., Broad, A., Govindan, R., \& Estrin, D. (2004, November). A wireless sensor network for structural monitoring. In Proceedings of the 2nd international conference on Embedded networked sensor systems (pp. 13-24). Acm. https://doi.org/10.1145/1031495.1031498

[21] Tavner, P. J., Xiang, J., \& Spinato, F. (2007). Reliability analysis for wind turbines. Wind Energy, 10(1), 1-18. https://doi.org/10.1002/we.204

[22] Musa, J. D. \& Okumoto, K. (1984, March). A logarithmic Poisson execution time model for software reliability measurement. In Proceedings of the 7th international conference on Software engineering (pp. 230-238). IEEE Press.

[23] Sharma, C., \& Gautam, D. K. (2015, October). Design development and implementation of wired Nurse calling system. In Green Computing and Internet of Things (ICGCIoT), 2015 International Conference on (pp. 1258-1262). IEEE. https://doi.org/10.1109/ICG CIoT.2015.7380657
[24] Aswin, S., Gopalakrishnan, N., Jeyender, S., Prasanna, R. G., \& Kumar, S. P. (2011, December). Design development and implementation of wireless nurse call station. In India Conference (INDICON), 2011 Annual IEEE (pp. 1-6). IEEE. https://doi.org/10.1109/INDCON.2011.6139633

[25] Ongenae, F., Duysburgh, P., Verstraete, M., Sulmon, N., Bleumers, L., Jacobs, A., ... \& De Turck, F. (2012, May). User-driven design of a context-aware application: an ambient-intelligent nurse call system. In Pervasive Computing Technologies User-driven design of a context-aware application: an ambient-intelligent nurse call system for Healthcare (PervasiveHealth), 2012 6th International Conference on (pp. 205-210). IEEE. https:// doi.org/10.4108/icst.pervasivehealth.2012.248699

[26] Mahmud, M. S., Majumder, M. A., Tushar, A. K., Kamal, M. M., Ashiquzzaman, A., \& Islam, M. R. (2017, December). Real-time feedback-centric nurse calling system with archive monitoring using Raspberry Pi. In Networking, Systems and Security (NSysS), 2017 4th International Conference on (pp. 1-5). IEEE. https://doi.org/10.1109/ NSYSS2.2017.8267799

[27] Khera, N., Tiwari, S., Singh, R. P., Ghosh, T., \& Kumar, P. (2016, October). Development of android based smart home and nurse calling system for differently abled. In Wireless Networks and Embedded Systems (WECON), 2016 5th International Conference on (pp. 1-4). IEEE. https://doi.org/10.1109/WECON.2016.7993423

[28] Ongenae, F., Strobbe, M., Hollez, J., De Jans, G., De Turck, F., Dhaene, T., ... \& Verhoeve, P. (2008, March). Ontology based and context-aware hospital nurse call optimization. In Complex, Intelligent and Software Intensive Systems, 2008. CISIS 2008. International Conference on (pp. 985-990). IEEE. https://doi.org/10.1109/ CISIS.2008.80

Víctor Eduardo Vélez Vargas received his Electronic Engineer degree from the Universidad Tecnológica de Pereira in May 2018. https://orcid.org/0000-00028888-8715

Carlos Alberto Henao Baena received his Electrical Engineer and Master in Electrical Engineering degrees from the Universidad Tecnológica de Pereira. Currently, he is the manager of the Electronics and Telecommunications line at the Tecnoparque Nodo Pereira. http://orcid.org/0000-0001-9873-8211

Andrés Felipe Calvo Salcedo received his Electronic Engineer degree in October 2012. His Master's degree in Electrical Engineering was received in November 2015. https://orcid.org/0000-0001-9409-8982 